\title{
Test Results and Predictions for the Response of Near-Ceiling Sprinkler Links in a Full-Scale Compartment Fire
}

\author{
LEONARD Y. COOPER and DAVID W. STROUP
}

US National Bureau of Standards

Gaithersburg, Maryland 20899, USA

\begin{abstract}
Data acquired during tests involving full-scale, sprinklered, compartment fires are presented and analyzed. Attention is focused on key features of the typical sprinkler link deployment/response problem. It is found that the elevated-temperature, smoke layer which develops inevitably in compartment fires can have a major impact on the thermal response of sprinkler links. It is shown that traditionally accepted methods of predicting sprinkler link response which do not account for this upper layer can be totally inadequate. Link response predictions used here involve a method of calculation which does take account of the smoke layer. Favorable comparisons between predictions and experiment are obtained and further validation of the method is recommended.

Finally, it is found that sprinkler link-to-ceiling spacing can have a significant effect on the thermal response of 1 inks and it is recommended that a method which accounts for this effect be developed and validated.
\end{abstract}

\section{BACKGROUND}

A series of full-scale, sprinklered, compartment fire tests were carried out [1]. One purpose of the test series was to study the response of sprinkler links and resulting sprinkler actuation during realistic compartment fire scenarios. This paper presents and analyzes a portion of the data acquired during the test program. It focuses attention specifically on key features of the typical sprinkler link deployment/response problem which are of such critical importance to fire safe design.

For any fire which develops in a given compartment configuration, the response of a sprinkler link is a function of 1) location and design of the link, and 2) time from fire initiation. Here, the location of the link is defined by the distance between the fire plume-ceiling impingement point (the point on the ceiling directly above the effective center of the fire) and the point on the ceiling directly above the effective center of the $1 \mathrm{ink}$, and by the distance of the 1 ink from the ceiling. The design of the link is characterized by the RTT (response time index). The RTI of a particular link is a measure of its rate-oftemperature change when immersed in a relatively uniform-velocity, uniform-temperature stream $[1,2]$. 
The effects of the link location parameters were of particular interest here. Also of key interest was the effect on link response of a changing, high temperature, upper-layer fire-generated environment which typically develops prior to link actuation in compartment fire scenarios. These effects, some of which are ignored in currently accepted sprinkler deployment technology [3-7], are studied here within the context of a growing fire in an office module-type scenario.

\section{THE NEAR-CEILING FIRE-GENERATED ENVIRONMENT AND RESPONSE OF SPRINKLER LINKS - EXPERIMENT MOTTVATION}

The Fire-Driven Ceiling Jet

As a fire grows, it releases energy and other products of combustion, both gaseous and solid. Because of their elevated temperature, the products of combustion, typically referred to as smoke, are driven upwards by buoyancy forces. These products generate a turbulent plume of upward moving, elevated temperature gases. A11 along the axis of the plume, relatively quiescent ambient air is entrained into and mixed with the plume gases as they continue their ascent to the ceiling. As a result of the entrainment, the total upward mass flux in the plume continuously increases and the average temperature in the plume continuously decreases with increasing height. When the upward movement of the plume gases is blocked by the compartment ceiling, they spread radially outward forming a relatively thin, high-temperature, highvelocity turbulent ceiling jet. Unlike the location of the unwanted fire and its plume which is not known a priori, the near-ceiling region is one zone in a compartment of fire origin where one is insured of a relatively intense fire enviromment. For this reason the near-ceiling region, i.e., the location of the ceiling jet, is a prime zone for the deployment of sprinklers and their heat sensitive actuating links. Effective and reliable selection and deployment of sprinkler links must be based on an understanding of the flow conditions in this zone, local to the Iink, which provide the driving mechanism for its response and actuation.

The Distribution of Velocity and Temperature Within the Ceiling Jet

As the gases of the ceiling jet flow radially outward under the ceiling surface from the region of fire plume-ceiling impingement, they entrain and mix with relatively cool gases from below. With increasing radius, this leads to a continuous increase in thickness and decrease in the peak temperature and velocity of the ceiling jet gases.

At any given radial position, the velocity and temperature of the ceiling jet varies significantly throughout its thickness. The velocity is always zero at the ceiling surface. Below the ceiling the velocity rises rapidly to its peak value. The velocity decreases with further increases in distance from the celling, until, at the local thickness of the ceiling jet, it approaches the negligible velocity of the lower, near-quiescent environment. Velocity distributions in ceiling jets have been measured [e.g., 8,9] and a general equation which predicts the velocity and correlates well these data has been developed [10]. The equation predicts the ceiling jet velocity distribution as a function of fire energy release rate, fire-to-ceiling spacing, distance from the fire plume-ceiling impingement point, and distance below the ceiling. 
The situation for the temperature distribution throughout the thickness of the ceiling jet is somewhat different than that of the velocity. Immediately adjacent to the ceiling itself, the temperature of the ceiling jet is identical to that of the ceiling surface. However, at any given radius this surface temperature is itself changing rapidly from its initial ambient-temperature state. Below the ceiling surface the temperature typically rises rapidly to its peak value and then decreases with increasing distance from the ceiling, approaching the temperature of the lower quiescent environment near the edge of the ceiling jet.

Significant progress has been made in the development of means to predict the radial- and time-dependent temperature of ceiling surfaces [11-13]. Also, temperature distributions of ceiling surfaces [14-16] and throughout ceiling jets $[\mathrm{e} . \mathrm{g}, \mathrm{1}, 15-19]$ have been measured in a variety of test configurations. However, as compared to the ceiling jet velocity distribution, a complete methodology for predicting the time- and spacedependent temperature distribution in the ceiling jet has not yet been assembled. Such a methodology could be used to enhance significantly the effectiveness and reliability of sprinkler link design and deployment.

\section{Effect of the Upper Hot Gas Layer}

Accepted design methods for predicting sprinkler link response are based on characteristics of fire plume-driven ceiling jets flowing beneath what are referred to as unconfined ceilings, i.e., ceilings without any confining walls. The unconfined ceiling configuration is associated usually with an idealized fire scenario. Real compartment fires typically involve structural walls that capture and contain firegenerated plume and ceiling jet gases. Throughout the early stages of a fire, these gases fill the space with an upper layer of smoke which grows continuously in thickness and in temperature. Usually, the growing smoke layex engulfs the ceiling jet rapidly, $i$, ,e, in time intervals which are comparable to the expected time of sprinkler actuation. Also, prior to sprinkler actuation the fire plume gases which drive the ceiling jet would have to travel a large part of their total fire-to-ceiling ascent through the elevated temperature upper smoke layer. As a result of all this, the characteristics of real fire plumes in the region of ceiling impingement and the characteristics of resulting plume-driven ceiling jets can differ significantly from those of idealized, unconfined ceiling, "design" fire scenarios. These upper layer effects have been modeled analytical1y $[11,20,21]$ and they have been observed experimentally $[16,18,22]$. Depending on the fire growth history and on the dimensions of the compartment, the effect of the upper layer and the ceiling structure can lead to link temperatures which are higher, and possibly even lower than corresponding link temperatures that would be measured in a comparable unconfined ceiling fire scenario.

\section{THE EXPERTMENT}

\section{General Remarks}

The purpose of this paper is to discuss those aspects of the experiments which bring into play and measure some of the above-mentioned effects of real compartment fires and corresponding sprinkler link response. Only those features of the experiments which were essential to this objective will be included here. For a comprehensive description of the overall test program the reader is referred to [1]. 
One test scenario is considered. It involves a wastepaper-basket fire initiation of an office-module compartment fire. The office furniture includes a desk, chair and bookcase, all heavily loaded with a paper/book-type fuel load. Referring to Fig. 1, the combustibles are assembled and the fire is initiated in the inside corner of a $2.44 \mathrm{~m} \mathrm{x}$ $3.66 \mathrm{~m}$ room of $2.44 \mathrm{~m}$ height. There is an open doorway to the room, 0.76 $\mathrm{m}$ wide $\mathrm{x} 2.03 \mathrm{~m} \mathrm{high}$, and this is located in the far $2.44 \mathrm{~m}$ wall. Smoke flowing out of the doorway is collected in a large hood/ventilated duct flow-through system equipped with oxygen-depletion-measurement capabilities. Data from this lead to an estimate of the time-dependent total energy release rate of the fire. The realistic, but relatively modest size of the test space, the general magnitude of the energy release rate of the fire and the size of the doorway are such as to lead to an upper layer in the burn room which would achieve very rapidly (compared to the response of sprinkler links) a deep, and relatively constant thickness.

Toward the center of the burn room is a "tree" of 20 mil diameter chromel-alume1, bare-wire thermocouples located at the ceiling and between the ceiling and floor at $0.152 \mathrm{~m}$ intervals. These are used to obtain the temperature in the burn room, away from the combustion zone and plume, as a function of time and elevation.

There is one active sprinkler and quick response link with RTI of 25 $(\mathrm{m} \cdot \mathrm{s})^{1 / 2}$. It is deployed in the center of the room, approximately $2.20 \mathrm{~m}$ from the room corner and from the fire plume-ceiling impingement point. The link is approximately $0.10 \mathrm{~m}$ below the ceiling surface. Also near the center of the room is a near-ceiling, vertical "tree" of five simulated sprinkler link disks each having an RTI of $25(\mathrm{~m} \cdot \mathrm{s})^{1 / 2}$. The disks are $0.0095 \mathrm{~m}$ in diameter and $0.00079 \mathrm{~m}$ thick. They are aligned with their axes parallel to the ceiling and in a near-optimum-streamline orientation in relation to a radial velocity ceiling jet. The ceilingto-simulated-1ink separation distances are indicated in Fig. 1 . There is a second, near-ceiling tree of simulated links located near the middle of the doorway. It is identical to the first tree except for the ceilingdisk separation distances whose values are also identified in Fig. 1. During the tests, temperatures of all simulated links were measured with thermocouples. Since the simulated links have the same RTI as the active link, their temperatures provide a direct indication of the effect of

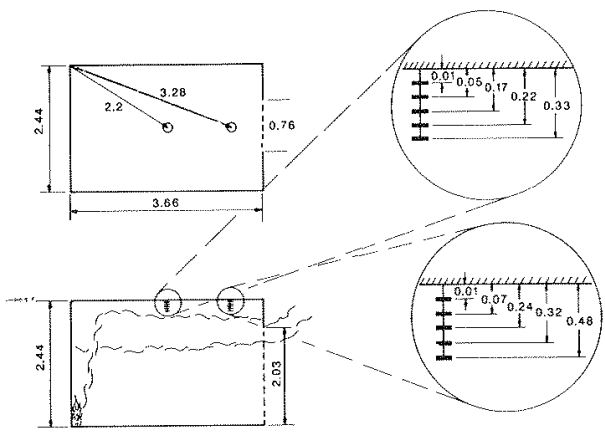

Fig 1 Sketch of test enclosure and positions (in m) of simulated links. 


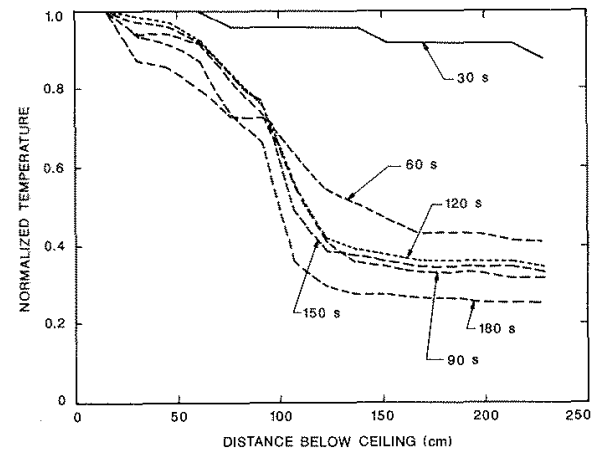

Fig 2 Normalized gas temperatures at specified times.

link-to-ceiling spacing (i.e, the effect of spatial distribution of ceiling jet velocity and temperature) on the response of an active link.

ANALYSIS AND DISCUSSION OF THE EXPERIMENTAL RESULTS

Temperatures in the Burn Room and Thickness of the Ceiling Layer

plots of temperature as a function of distance from the ceiling as measured by the floor-to-ceiling thermocouple tree are presented in Fig. 2 for different times into the fire, but prior to sprinkler activation which occured at approximately $175 \mathrm{~s}$. These temperatures (C)

distributions have been normalized by the temperature (C) measured at the thermocouple $0.152 \mathrm{~m}$ below the ceiling. It can be noted that 1 ) an upper, elevated-temperature gas layer grows rapidly to a relatively constant thickness; 2) there is an interface that separates these upper layer gases from a relatively low-temperature and spatially-uniform lower layer; and 3) the interface is at a near-constant elevation approximately $0.99 \mathrm{~m}$ below the ceiling ( $1.45 \mathrm{~m}$ above the floor), corresponding to an elevation of $0.58 \mathrm{~m}$ below the top of the doorway.

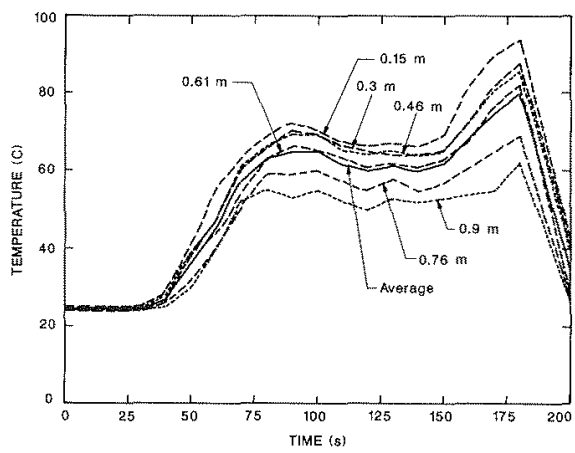

Fig 3 Measured upper layer gas temperatures at different distances below ceiling and average (solid curve) upper layer gas temperature. 


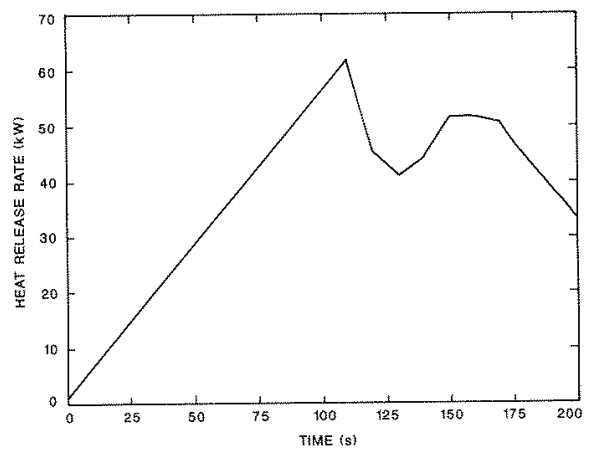

Fig 4 Heat release rate.

Based on the above observations, the above-interface temperatures were averaged spatially for each time. The average upper-1ayer temperature vs time, is plotted in Fig. 3 and used below in the analysis of link response. Also plotted in Fig. 3 are the temperature-time measurements of all upper-layer-submerged thermocouples. Activation of the active sprinkler head is seen to occur at approximately $175 \mathrm{~s}$.

\section{Heat Release as a Function of Time}

The total heat release of the combustibles vs time was deduced from oxygen depletion calorimetry measurements acquired with the hood/duct of a smoke collection/exhaust system [23]. The result, presented in Fig. 4, wi11 be used to predict the thermal response of the simulated sprinkler links and to compare these predictions to measured time-temperature data.

\section{Response of the Simulated Links}

The measured temperature responses of the two trees of simulated links are plotted in Figs. 5 and 6 for the room-center tree and the near-

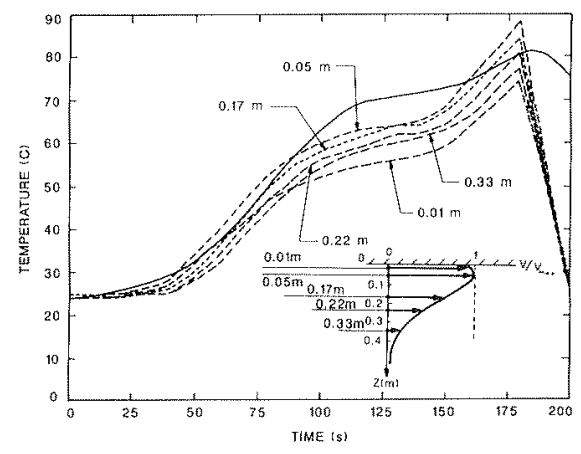

Fig 5 Measured simulated link temperatures at different distances below ceiling, calculated temperature of a near-ceiling link (solid plot), and predicted celiting jet velocity profile: center of room. 


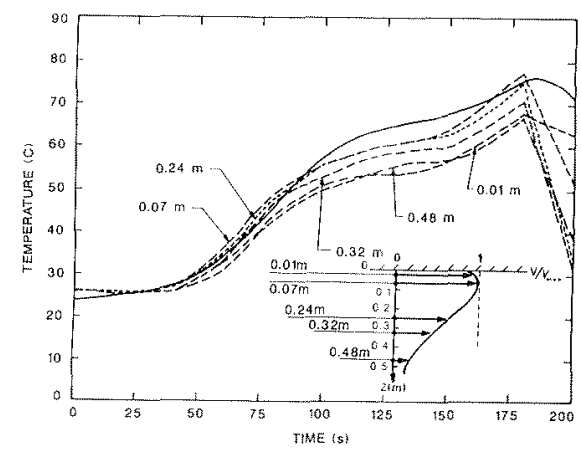

Fig 6 Measured simulated link temperatures at different distances below ceiling, calculated temperature of a near-ceiling link (solid plot), and predicted ceiling jet velocity profile: near doorway.

doorway tree locations, respectively. Included in these figures are theoretical estimates for the normalized velocity, $V / V_{\max }$, of the smoke as it flows past each link of the two simulated link trees, Here, $V_{\max }$ is the maximum ceiling jet velocity at the ceiling position of interest. The velocities are computed from Eq. (1) of [10].

The thermal response of a sprinkler link is determined by and depends on the local "free-field" gas temperature and velocity. From the plots of predicted velocity, a significant variation in link response as a function of ceiling elevation is to be expected and was measured. For example, for the link tree at the center of the room, near the deployed active sprinkler, it is seen in Fig. 5 that at the time of sprinkler actuation the coolest of the links was the one $0.01 \mathrm{~m}$ below and closest to the ceiling. At this time, that link was $14^{\circ} \mathrm{C}$ less than the hottest of the center-room links which reached approximately $64^{\circ} \mathrm{C}$ above ambient (i.e., $88^{\circ} \mathrm{C}$ ) and was located $0.05 \mathrm{~m}$ below the ceiling. Similarly, for the near-doorway tree, it is seen in Fig. 6 that at the time of sprinkler actuation the coolest of the links was, again, the one $0.01 \mathrm{~m}$ below and closest to the ceiling. At this time, that link was $10^{\circ} \mathrm{C}$ less than the hottest of the neax-doorway links which reached approximately $53^{\circ} \mathrm{C}$ above ambient (i.e., $77^{\circ} \mathrm{C}$ ) and was located $0.07 \mathrm{~m}$ below the ceiling.

It is particularly noteworthy that all accepted and recently proposed methods of estimating sprinkler link response (e.g., $[3,5-7\}$ ) are based on estimates of peak velocity and temperature. These depend only on radial distance from the fire and not on distance from the ceiling. Provided a link is located within a relatively wide range of below-ceiling elevations, but not too close or too far, the relatively broad velocity distributions and measured link temperatures of Figs. 5 and 6 are consistent with the fact that the traditional approach is a reasonable one. However, for more reliable and versatile design, especially for links very close to ceilings, it is evident that predictions of the response of a link must be determined as a function of the vertically-varying, local, free-field gas environment.

The accepted approach to sprinkler link deployment is based on link response calculations which are strictly valid only for links deployed below unconfined ceilings, $i, e .$, where there is no growth of an upper smoke layer. To the extent that they generate reliable results in such 


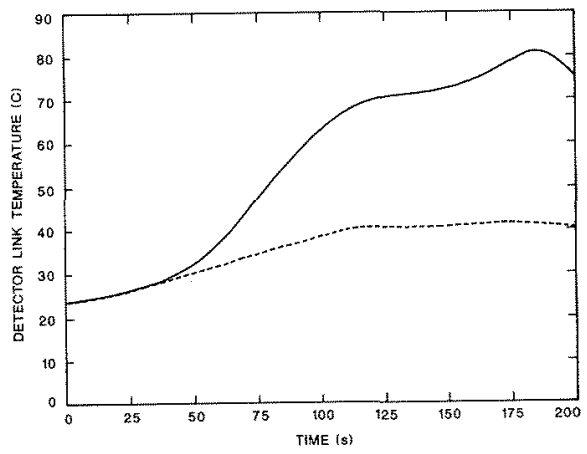

Fig 7 Calculated link temperature with (solid curve) and without (dotted curve) upper layer: center of room.

configurations they can also provide reasonable engineering estimates of link response relatively early in time for confined ceilings. However, for most of the time interval between fire initiation and sprinkler actuation, ceiling jets and sprinkler links are typically submerged in a hot upper smoke layer. For this reason, such calculation procedures do not have general applicability. This is illustrated graphically in the dashed plot of Fig. 7 which is the result of an unconfined ceiling calculation for the link temperature response in the present experiment for the center-room deployed links. Reference [23] includes a plot of a similar result for the near-doorway links. The calculations used the DETACT-QS computer program [6], the energy release rate history of Fig. 4 , and a $25(\mathrm{~m} \cdot \mathrm{s})^{1 / 2}$ RTI. The predicted link thermal responses are far lower than would be required to predict the observed, $175 \mathrm{~s}$ sprinkler actuation. It is clear that a design procedure which uses predictions of unconfined ceiling link response is not adequate in the present type of typical fire scenario.

As mentioned earlier, calculation procedures for link response which take account of the effect of the upper layer on peak ceiling jet gas velocity and temperature (but not yet the link-to-ceiling spacing) have been developed $[11,20,21]$. These have been applied in the present fire scenario and the results are presented in the solid line plots of Fig. 7 for a center-room link. A similar result for a near-doorway 1 ink is presented in Reference [23]. The Fig. 7 result predicts that a 25 $(\mathrm{m} \cdot \mathrm{s})^{1 / 2} \mathrm{RTI}, 74^{\circ} \mathrm{C}$ fuse-temperature link would fuse at approximately the same time, $175 \mathrm{~s}$, that the experimental link and sprinkler were actuated.

The calculated two-layer link responses are replotted in Figs. 5 and 6. As can be seen in these figures, the predicted link response is remarkably close to measured values. These favorable results provide very encouraging support for the link response prediction methodology used which has, heretofore, never been evaluated experimentally.

\section{SUMMARY OF CONCLUSIONS AND RECOMENDATIONS FOR FURTHER RESEARCH}

This paper presented and analyzed a portion of the data acquired during a test program which involved full-scale, sprinklered, compartment fires. The work here focused attention specifically on key features of 
the typical sprinklex link deployment/response problem. The following is a summary of conclusions and recommendations for futher research:

The elevated temperature, upper smoke layer which develops inevitably in compartment fires can have a major impact on the thermal response of sprinkler links. As was the case in the experiment discussed here, traditionally accepted methods of predicting sprinkler link response can be totally inadequate. This is because of the fact that such methods are based on idealized, unconfined ceiling fire scenarios, and they do not account for the effects of the smoke layer on the flow dynamics of the upper fire plume and on the ceiling jet, the latter of which engulfs and drives the thermal response of the sprinkler link.

The 1 ink response predictions of this work used a new method of calculation which does take account of the smoke layer environment. Favorable comparisons between predictions and experiment wexe obtained. While this is very encouraging, before this new method can be recommended for general use it should be validated over a range of experimental conditions. Toward this end it is recommended that an experimental program be carried out in which link responses are measured under confined ceiling conditions involving a range of: link RTI, link-to-fire spacing, link-to-ceiling spacing, fire-to-ceiling spacing, fire growth rate, and ceiling material. It is noteworthy that no such validation exists for the sprinklex link response calculation procedure which was used, for example, to develop the standard of [5].

Sprinkler link-to-ceiling spacing can have a significant effect on. the thermal response of links. For example, in the present experiment, at the time of fusing of the active link (designed to occur at $74^{\circ} \mathrm{C}$ ) the temperatures of nearby, like-RII, simulated links at $0.01 \mathrm{~m}$ and $0.05 \mathrm{~m}$ below the ceiling varied by approximately $14^{\circ} \mathrm{C}$, with the link closer to the ceiling being the cooler of the two. This can be of critical importance, especially in the reliable use of certain modern sprinklerlink systems which are often deployed very close to, and even embedded into ceiling surfaces. A method is nearly at hand to include the effect of link-to-ceiling spacing in link response predictions. It is recommended that development of such a method be completed and validated with the data base generated by the above-recommended test program.

\section{AGKNOWLEDGMENTS}

This work was supported by the U.S. Fire Administration. The authors would like to express their appreciation to Edward Wall and Tom Smith for their continued interest in this area of study.

\section{REFERENCES}

1. Walton, W.D., Budnick, E.K., Quick Response Sprinklers in Office Configurations: Fire Test Results, NBSIR 88-3695, US Nat Bur Stand, Gaithersburg MD, 1988 .

2. Heskestad, G., The Response Time Index (RTI), Tech Conf on Residential Sprinklers, Fact Mut Res Corp, Norwood MA, 1981.

3. Evans, D.D., Thermal Actuation of Extinguishing Systems, Comb Sci Tech, Vo1 40, pp79-92, 1984.

4. Alpert, R.L., Calculation of the Response Time of Ceiling-Mounted Fire Detectors, Fire Tech, Vol 8, pp181-195, 1972. 
5. Standard on Automatic Fire Detectors, NFPA 72E - 1984, Appendix C, Nat1 Fire Prot Assoc, Batterymarch Park, Quincy MA.

6. Evans, D.D. and Stroup, D.W., Methods to Calculate the Response Time of Heat and Smoke Detectors Installed Below Large Unobstructed Ceilings, Fire Tech, Vo1 22, pp54-65, 1986.

7. Stroup, D.W., Evans, D.D., and Martin, P., Evaluating Thermal Detection Systems, NBS Spec Publs 712 and 713, US Nat Bur Stand, Gaithersburg MD, 1986.

8. Alpert, R.1., Turbulent Ceiling-Jet Induced by Large-Scale Fires, Comb Sci Tech, Vo1 11, pp197-213, 1975.

9. Motevalli, V., et al, Measurements of the Transient Temperature and Velocity Profiles in Ceiling Jets, Proc 1986 Fall Tech Mtg East Sec Comb Inst, Comb Inst, Pittsburg PA.

10. Cooper, L.Y., Ceiling Jet-Driven Wall Flows in Compartment Fires, NBSTR 87-3535, US Nat Bur Stand, Gaithersburg MD, 1987.

11. Cooper, L.Y., Heat Transfer to Ceilings Above Enclosure Fires, 19 th Symp (Internat) Comb, Comb Inst, Pittsburgh PA, pp933-939, 1982.

12. Cooper, L.Y. and Woochouse, A., The Buoyant Plume-Driven Adiabatic Ceiling Temperature Revisited, J Heat Trans, Vol 108, pp822-826, 1986.

13. Cooper, L.Y. and Stroup, D.W., Thermal Response of Unconfined Ceilings Above Growing Fires and the Importance of Convective Heat Transfer, J Heat Trans, Vo1 109, pp172-178, 1987.

14. Woodhouse, A., Marks, C.H., and Cooper, L.Y., An Experimental Study of the Transient Thermal Response of Unconfined Ceilings Above Fire Plumes, Proc 1987 ASME-JSME Thermal Eng Conf, Vol 1, pp. 387-394, ASME, NY NY.

15. Veldman, C.C., Kubota, T., and Zukoski, E.E., An Experimental Investigation of the Heat Transfer from a Buoyant Gas Plume to a Horizontal Ceiling - Part 1. Unobstructed Ceiling, NBS-GCR-77-97, by Cal Inst Tech for US Nat Bur Stand, Gaithersburg MD, 1975.

16. Zukoski, E.E. and Kubota, T., An Experimental Investigation of the Heat Transfex from a Buoyant Gas Plume to a Horizontal Ceiling Part 2. Effects of Ceiling Layer, NBS-GCR-77-98, by Cal Inst Tech for US Nat Bur Stand, Gaithersburg MD, 1975.

17. You, H.-Z. and Faeth, G.M., An Investigation of Fire Impingement on a Horizontal Ceiling, by Penn State Univ for US Nat Bur Stand, Gaithersburg MD, 1979.

18. Stroup, D.W., Development of an Automated Probe Positioner for Measurements in Fire-Generated Plumes and Ceiling Jets, NBSIR 86 3379, US Nat Bur Stand, Gaithersburg MD, 1986.

19. Heskestad, $G$. and Hamada, T., Ceiling Flows of Strong Fire Plumes, FMRC Rpt J I OKOE1. RU 070(A), Fact Mut Res Corp, Norwood MA, 1984.

20. Cooper, L.Y., A Buoyant Source in the Lower of Two, Homogeneous, Stably Stratified Layers, 20th Symp (Internat) Comb, Comb Inst, pittsburgh PA, pp1567-1573, 1984.

21. Evans, D.D., Galculating Fire Plume Characteristics in a Two-Layer Environment, Fire Tech, Vol ?0, pp39-63, 1984.

22. Evans, D.D. and Morehart, J., Investigation of the Effects of a Stratified Two Layer Environment on Fire Plume Temperatures, Proc 1987 ASME-JSME Thermal Eng Conf, Vol 1, pp387-394, ASME, NY NY. Proceedings of the 1987 ASME-JSME Thermal Engineering Conference,

23. Cooper, L.Y. and Stroup, D.W., Test Results and Predictions for the Response of Near-Ceiling Sprinkler Links in a Ful1-Scale Compartment Fire, NBSIR-87-3663, US Nat Bur Stand, Gaithersburg MD, 1987. 